\title{
BOOK TRAILERS NA EDUCAÇÃO PROFISSIONAL E TECNOLÓGICA: UM ESTUDO COM DISCENTES DO CURSO DE COMPUTAÇÃO GRÁFICA DO IFPE - CampusOLINDA
}

\author{
Lucas Rodrigo Santos de Almeida*, Eugênia de Paula Benício Cordeiro \\ E-mail: *lucasalmeidarecife@gmail.com \\ Centro Universitário Joaquim Nabuco \\ DOI: $10.15628 /$ rbept.2020.8083
}

Artigo submetido em: dez./2018 e aceito em: jun./2018

\begin{abstract}
RESUMO
O book trailer é um instrumento pedagógico que une literatura, tecnologia e cinema a fim de desenvolver uma leitura enriquecedora da realidade. Desse modo, o objetivo geral deste trabalho foi investigar como a criação de book trailers, por discentes do Curso Técnico de Computação Gráfica do Instituto Federal de Pernambuco - Campus Olinda pode contribuir para o estímulo à leitura em uma perspectiva de formação profissional e tecnológica. Metodologicamente a pesquisa dividiu-se em: pesquisa-ação, exploratória, qualitativa, bibliográfica, documental e de campo no IFPE - Campus Olinda. Ao final, comprovou-se que o book trailer é uma ferramenta lúdica, emotiva e inovadora, o qual pode estimular o interesse, a curiosidade e o hábito da leitura para o sujeito-leitor.
\end{abstract}

Palavras-Chave: Book trailer. Sujeito-leitor. Leitura. Tecnologias da Informação e Comunicação. Educação Profissional e Tecnológica.

\section{BOOK TRAILERS IN PROFESSIONAL AND TECHNOLOGICAL EDUCATION: A STUDY WITH STUDENTS OF THE IFPE - COLLEGE OLINDA}

\begin{abstract}
The book trailer is a teaching tool that combines literature, technology and cinema in order to develop an enriching reading of reality. Thus, the general objective of this work was to investigate how the creation of book trailers, by students of the Technical Course of Computer Graphics at the Federal Institute of Pernambuco - Campus Olinda, can contribute to stimulate reading in a perspective of professional and technological training. Methodologically the research was divided into: action research, exploratory, qualitative, bibliographic, documentary and field at IFPE - Campus Olinda. In the end, it proved that the book trailer is a playful, emotional and innovative tool, in which it can stimulate interest, curiosity and the habit of reading for the subject-reader.
\end{abstract}

Keywords: Book trailer. Subject-reader. Reading. Information and Communication Technology. Professional and Technological Education. 


\section{INTRODUÇÃO}

No contexto do "reinventar" e do "reaprender" (ALMEIDA, 2017) as editoras de livros tiveram que se adaptar aos novos artifícios tecnológicos, por exemplo, a criação de book trailers que são ferramentas de divulgação literária os quais incorporam elementos do cinema ao universo literário, utilizando-se do ambiente virtual para divulgação e venda de livros de escritores (SANTOS; GIRÃO, 2013). Segundo Souza e Costa (2012), os book trailers trazem uma abordagem distinta dos trailers de cinema, pois eles montam frases de impacto para chamar a atenção do leitor, permeadas de imagens, cenas e histórias do livro, tendo um fundo musical.

Assim sendo, a proposta deste trabalho é distinta da concepção mercadológica, pois percebemos que a utilização do book trailer pode auxiliar na aprendizagem e na formação leitora do discente em espaços formais e informais. Nessa linha de raciocínio, o artigo destina-se a uma concepção de formação de sujeito-leitor omnilateral (RAMOS, 2008), isto é: questionador, crítico, transformador da sua própria realidade, onde a leitura vai além do caráter conteudístico/utilitário, mas, sim, visando à formação humana integral.

Com base no contexto apresentado, a pesquisa se deu com discentes do Curso Técnico de Computação Gráfica do IFPE - Campus Olinda localizado no bairro de Casa Caiada, município de Olinda-PE. Após análise documental do Projeto Pedagógico do Curso verificou-se que não há projeto ou atividade de extensão para estimular a leitura em sala de aula ou em outros espaços informais. Sendo assim, este trabalho se propôs a realizar uma pesquisa de campo para constatar preliminarmente, por meio de questionário, a preferência dos discentes pela leitura em sala de aula, 0 quantitativo de livros que leem ao ano, o uso da biblioteca para a leitura, o uso de tecnologias educacionais para auxiliar a leitura em sala de aula, a percepção no tocante às vantagens dos book trailers para a construção do aprendizado dentre outras questões.

Destarte, o artigo apresenta o seguinte questionamento: como a criação de book trailers, por discentes do Curso Técnico em Computação Gráfica do Instituto Federal de Pernambuco - Campus Olinda pode contribuir para o estímulo à leitura em uma perspectiva de formação profissional e tecnológica?

O objetivo geral é investigar como a criação de book trailers, por discentes do Curso Técnico de Computação Gráfica do Instituto Federal de Pernambuco - Campus Olinda pode contribuir para o estímulo à leitura em uma perspectiva de formação profissional e tecnológica.

A justificativa central deste artigo refere-se à escassez de leitura na sociedade brasileira. De acordo com a pesquisa Retratos da Leitura no Brasil (2016) realizada em 2015, aproximadamente, 104,7 milhões de brasileiros (56\%) são considerados "leitores" - por terem lido um livro, inteiro ou em partes, nos últimos três meses; e cerca de 83 milhões de habitantes (44\%) 
são considerados "não leitores". Em relação à leitura anual per capita - por indivíduo - o brasileiro lê em média 4,96 livros por ano. Além desses dados, a pesquisa informa que $23 \%$ dos brasileiros não gostam de ler e $30 \%$ nunca compraram um livro. Em relação à região Nordeste, o quantitativo de livros por habitante/ano está abaixo da média nacional, sendo 3,93 livros, além disso, $51 \%$ dos nordestinos são considerados leitores e $49 \%$ não leitores, em tese, metade da região é leitora e a outra metade não leitora.

Quanto aos procedimentos metodológicos utilizou-se a técnica de pesquisa-ação a fim de diagnosticar a realidade social do Curso de Computação Gráfica referente à leitura em espaços formais e informais, para isso utilizou-se um questionário, direcionado à quatorze discentes do Curso de Computação Gráfica.

O artigo divide-se em: Introdução, Metodologia, Resultados e Discussões, Considerações finais e Referências.

\section{METODOLOGIA}

Foram consultadas a Matriz do Curso Técnico de Computação Gráfica e o Projeto Pedagógico do Curso para análise do contexto social, regional, pedagógico - do Curso e do IFPE - Campus Olinda. Geograficamente a pesquisa foi realizada no IFPE - Campus Olinda, localizado no bairro de Casa Caiada, município de Olinda-PE. O Curso Técnico de Computação Gráfica - criado em 2014 - tem duração de 3 semestres ( 1 ano e 6 meses), com o objetivo de formar profissionais habilitados na área de Computação Gráfica, para atuação no mercado de trabalho, contemplando áreas inovadoras do conhecimento e tecnologias modernas. O foco central do Curso é o desenvolvimento de competências e habilidades, conforme as demandas do mercado de trabalho na área de Computação Gráfica (IFPE, 2014).

Em alguns trechos do Projeto Pedagógico do Curso, encontram-se contradições, pois o curso visa a uma formação humanista e, ao mesmo tempo, corrobora para que o aluno aplique tais conhecimentos no mercado de trabalho ou no "mundo do trabalho". Tal concepção adotada - Projeto Pedagógico do Curso -, não está relacionada à concepção cidadã, sendo, do sujeito-leitor omnilateral, ou seja, uma formação leitora cidadã, crítica e emancipadora, que se preocupa com a formação humana integral, na qual o sujeito é visto como produtor e modificador da sua realidade (RAMOS, 2008; SAVIANI, 2001, CIAVATTA, 2005; MORAIS; HENRIQUE, 2017), distintamente, da formação utilitarista/conteudística - em que o sujeito-leitor é distorcido e alienado da sua realidade, em que a sua formação leitora destina-se a um fim (prático) pré-estabelecido.

Em relação aos sujeitos da pesquisa selecionou-se - por amostragem - quatorze discentes do 3 o período, do Curso Técnico de Computação Gráfica, Turno Matutino, da disciplina de Áudio e Vídeo. O uso da amostragem permite que a pesquisa seja realizada dentro de um pequeno 
grupo de pessoas, estatisticamente representativa do universo estudado (THIOLLENT, 2011). O critério de escolha da amostra se deu a partir do último período do Curso (3ำ período) e da disciplina de Áudio e Vídeo. Nesta disciplina, os alunos: conhecem conceitos sobre música, som e efeitos sonoros; distinguem os diversos formatos de arquivos e programas de áudio e vídeo; e aplicam conhecimentos sobre edição de áudio e vídeo (IFPE, 2014).

Em relação aos objetivos, o estudo é de caráter exploratório, pois visa "desenvolver, esclarecer e modificar conceitos e ideias realizado especialmente quando o tema escolhido é pouco explorado [...]" (GIL, 2008, p. 28). Na fase de exploratória, os discentes responderam a um questionário composto por dez questões - com perguntas abertas e fechadas.

Quanto ao objeto de estudo, o presente trabalho teve como estratégia a pesquisa-ação, que é um tipo de pesquisa na qual a interação e o envolvimento entre os agentes - pesquisador e pesquisados - são essenciais para a intervenção na realidade social (PRESTES, 2003; GIL, 2008). O enfoque da pesquisa-ação está na interpretação do mundo a partir da visão dos sujeitos da investigação, entretanto, para isso se concretizar, torna-se essencial a confiança mútua - dos agentes - durante a pesquisa (FERNANDES; GOMES, 2003). ação:

Numa explicação abrangente, Thiollent (2011) define a pesquisa-

é um tipo de pesquisa social com base empírica que é concebida e realizada em estreita associação com uma ação ou com a resolução de um problema coletivo e no qual os pesquisadores e os participantes representativos da situação ou do problema estão envolvidos de modo cooperativo ou participativo (THIOLLENT, 2011, p. 20-23).

Diferentemente do método científico clássico, podemos inferir que a pesquisa-ação promove a "união" dos esforços entre os agentes da pesquisa, cria alternativas e busca estratégias e ações para intervir e, consequentemente, melhorar a realidade social. O "implantar", o "transformar" e o "agir" são os verbos inerentes à pesquisa-ação.

Nos resultados e discussões realizou-se a análise interpretativa de natureza qualitativa, devido à possibilidade de explorar, conceitos e representações sobre o tema em questão (GASKELL, 2002), além de possibilitar ao pesquisador fazer alegações com base em perspectivas construtivistas e participativas (CRESWELL, 2007).

\section{RESULTADOS E DISCUSSÕES}


Ao total, quatorze questionários foram respondidos em sala de aula, isto é, todos os discentes responderam. Em tese: foi possível diagnosticar as impressões da turma em relação à utilização da leitura com a tecnologia em sala de aula, sendo, o questionário correspondente à fase exploratória da pesquisa-ação; e a amostragem referindo-se ao quantitativo de pessoas.

Em relação à média de idade dos discentes, estes possuem aproximadamente 19 (dezenove) anos de idade. Quanto à formação, estão no último período do Curso Técnico de Computação Gráfica e não possuem outra titulação - Graduação, Especialização, Mestrado ou Doutorado. Quanto ao gênero, dez discentes são do gênero masculino e quatro discentes do gênero feminino. Em seguida, realizaram-se a análise e interpretação dos dados, por meio, da discussão dos dados empíricos do questionário, juntamente, com a revisão bibliográfica dos temas: book trailer, Tecnologias da Informação e Comunicação, sujeito-leitor, leitura e as estatísticas da Pesquisa Retratos da Leitura (2016).

FIGURA 1: quadro com preferências de leitura

\begin{tabular}{|c|c|}
\hline VOCÊ GOSTA DE LER? & $\%$ \\
\hline Sim & 78,57 \\
\hline Não & 21,42 \\
\hline Você prefere: & $\%$ \\
\hline Leitura individual & 100,00 \\
\hline Leitura coletiva & 0,00 \\
\hline
\end{tabular}

Fonte: desenvolvido pelos autores (2020)

No primeiro quesito, $78,57 \%$ dos discentes - a maioria - afirmaram que gostam de ler, no entanto, $21,42 \%$ discentes assinalaram que não possuem o gosto pela leitura. O quantitativo de "não leitores" é dado um relevante e questionador, pois, como um discente pode estar matriculado numa instituição educacional, sem gostar de ler? Sabendo-se que a leitura é necessária para apresentação de trabalhos, crescimento intelectual, aprovação nas disciplinas, formação humana, conhecimento de outras línguas etc. Dados recentes, comprovam esse cenário "delicado" - $23 \%$ dos brasileiros não gostam de ler. (RETRATOS DA LEITURA, 2016).

Outras estatísticas pontuam que $67 \%$ daqueles que têm entre $18-24$ anos se declaram leitores e 33\% não leitores (RETRATOS DA LEITURA, 2016). Contrário ao pessimismo "apocalíptico", Ceccantini (2016) advoga que no seio educacional frases como "os jovens não leem" ou "os jovens não 
gostam de ler", trata-se de um discurso anacrônico, que parece mais singelo traduzir a incapacidade da instituição de ensino - de enfrentar os novos desafios pedagógicos frente às mudanças da sociedade globalizada - do que fazer um diagnóstico acurado dos fenômenos em curso.

Na segunda questão, $100 \%$ dos discentes priorizam a leitura individual em relação à leitura coletiva. Geralmente, identifica-se que a leitura se dá de modo individual e/ou "solitário", no entanto, a concepção de uma leitura coletiva só é possível por meio da apresentação de trabalhos ou explanações orais em sala de aula. Acerca dessa questão, vários autores trabalham com diversas propostas de leitura grupal ou coletiva, por exemplo: leitura de $e$ books por meio de uma rede social (LIU, 2009); criação de clubes de leitura em bibliotecas e/ou redes sociais (RODRÍGUEZ, 2012; MOREIRA, 2010); discussão em grupo com foco no compartilhamento de experiências de leitura (LIMA, 2016) etc.

FIGURA 2: quadro com livros e leituras

\begin{tabular}{|c|c|}
\hline \begin{tabular}{|c|} 
Quantos livros você lê \\
ao ano?
\end{tabular} Nenhum & $\%$ \\
\hline $1-5$ livros & 21,42 \\
\hline $6-10$ livros & 64,28 \\
\hline $11-15$ livros & 7,14 \\
\hline 16 livros ou mais & 7,14 \\
\hline Você prefere a leitura de livro: & 0,00 \\
\hline Digital/e-book & $\%$ \\
\hline Físico/impresso & 7,14 \\
\hline Em ambos & 57,14 \\
\hline
\end{tabular}

Fonte: desenvolvido pelos autores

A Pesquisa Retratos da Leitura (2016) descreve que o brasileiro lê, em média, 5 (cinco) livros ao ano, nesse sentido, a pesquisa corrobora com a questão "Quantos livros você lê ao ano?", no qual a maioria dos discentes (64,28\%) leem entre "1-5 livros" ao ano. Esse quantitativo de leitura é análogo às estatísticas da Região Nordeste, em que o habitante/ano lê, em média, 4 (quatro) livros ao ano. (RETRATOS DA LEITURA, 2016).

Quantos aos discentes que não leram nenhum livro ao ano, temos $21,42 \%$. Quanto aos que leram "6-10 livros" e "11-15 livros" o percentual empatou em $7,14 \%$; em relação à leitura de "16 livros ou mais", esperava-se - de acordo com as estatísticas nacionais - que seria ínfima o quantitativo de 
leitores. Essas estatísticas confirmam que a construção de um "país leitor" tornou-se numa tarefa complexa, pois as políticas públicas implantadas, raramente, "[...] desenvolveram esforços verdadeiros e de alcance nacional na formação de leitores plenos, minimizando a importância dessa formação nos currículos e nas práticas educacionais e culturais, realmente fica difícil compreender avanços". (MARQUES NETO, 2016, p. 62).

No quesito "Você prefere a leitura de", os discentes assinalaram que a leitura em "livro impresso/físico" é o preferencial, sendo registrado em $57,14 \%$. Apesar dos discentes estarem vinculados a um curso de Computação Gráfica, apenas, $7,14 \%$ dos entrevistados preferem a leitura, exclusivamente, no livro digital. $\mathrm{Na}$ estatística nacional, os livros digitais apresentam um percentual de $26 \%$ (entre os que leram) e $74 \%$ (entre os que não leram) (RETRATOS DA LEITURA, 2016). Em comparação à literatura abordada, percebe-se que o livro impresso não foi extinto (FARINACCIO, 2016), mas, sim, tornou-se um complemento e as pessoas continuam a lê-los (SANTAELLA, 2012; FARINACCIO, 2016), conforme, se comprovou nesse quesito. Adendo a isso, "[...] o que não se deve perder de vista é o prazer por esse texto, o prazer pela e na leitura. [...] toda leitura se dá no e pelo diálogo, um diálogo que conduz ao autodiálogo". (GUIDA, 2012, p. 7).

FIGURA 3: quadro sobre leituras em espaços formais e informais

\begin{tabular}{|c|c|}
\hline $\begin{array}{c}\text { Em relação aos espaços formais e informais de leitura, } \\
\text { você prefere ler: }\end{array}$ & $\%$ \\
\hline Sala de aula & 7,14 \\
\hline Livraria & 0,00 \\
\hline Biblioteca & 0,00 \\
\hline Residência & 85,71 \\
\hline Outro & 7,14 \\
\hline
\end{tabular}

Fonte: desenvolvido pelos autores (2020)

Nesta questão encontrou-se na primeira posição a "residência", como local de maior preferência da leitura (85,71\%). Essa alternativa corrobora com os $81 \%$ dos brasileiros que preferem à leitura em "casa" (RETRATOS DA LEITURA, 2016). É possível que a residência seja um local mais cômodo para a leitura. O local da "sala de aula" e o "ônibus/metrô" (corresponde à alternativa "outro") aparece com 7,14\%.

O aspecto negativo do questionário está na escassez de leitura na biblioteca. A Pesquisa Retratos da Leitura (2016) identifica que a "sala de aula" é o segundo local mais propício à leitura (25\%) e "bibliotecas em geral" aparece na terceira colocação, com 19\%. Diante dessas estatísticas, podemos fazer as seguintes indagações: Por que a sala de aula e a 
biblioteca, como espaços formais de aprendizagem, são pouco atrativos para à leitura dos discentes? A sala de aula é o espaço formal que os discentes realizam as atividades, porém por que este local não é o mais costumeiro para a realização das leituras? Será que a sala de aula não instiga os discentes a lerem?

Por estarem inseridos na era pós-digital, os alunos tendem a ter uma familiaridade com a tecnologia e os docentes devem acompanhar essas mudanças. Desse modo, torna-se essencial exercer as atividades de leitura em diversos espaços, não restringindo-se à sala de aula, apenas (PETARNELLA; GARCIA, 2010). Outras pesquisas apresentam resultados positivos quanto à utilização de instrumentos didáticos para a realização de leitura (não apenas em sala de aula), por exemplo: leitura, pesquisa e postagem de gêneros literários por meio de grupo do WhatsApp (ANDRADE, 2016); utilização do Facebook nas aulas de língua portuguesa, com a participação e interação dos alunos na rede social (fora do horário de aula) (CAVALCANTE, 2015).

Diante do contexto, é possível afirmarmos que a utilização dos espaços informais (residência, metrô, parques, praças) podem oferecer resultados mais significativos para a prática da leitura, mesmo assim, é notório que tanto a instituição de ensino como os docentes proponham ações que visem estimular a leitura dentro dos ambientes formais (biblioteca, sala de aula), se possível, com a utilização da tecnologia.

Segundo a pesquisa Retratos da Leitura (2016), 14\% dos brasileiros afirmam que a biblioteca é "um lugar para lazer ou passar o tempo". Essa informação pode representar a biblioteca como um espaço destinado, apenas, a estudar e pesquisar livros, destinado aos discentes e docentes. $\mathrm{Ou}$ seja, a biblioteca é vista como um espaço de leitura utilitária.

FIGURA 4: quadro sobre biblioteca e formação leitora

\begin{tabular}{|c|c|}
\hline \begin{tabular}{|c|}
\hline Com que frequência, anualmente, \\
\hline você realiza leituras na biblioteca do IFPE-Olinda?
\end{tabular} & $\%$ \\
\hline Nenhuma vez & 92,85 \\
\hline $1-5$ vezes & 7,14 \\
\hline $6-10$ vezes & 0,00 \\
\hline 11 vezes ou mais & 0,00 \\
\hline \begin{tabular}{|c|} 
Acerca da sua formação como sujeito-leitor, quais pessoas lhe \\
influenciaram no hábito da leitura:
\end{tabular} & $\%$ \\
\hline Nenhuma & 21,42 \\
\hline Pais/Mães & 7,14 \\
\hline Familiares & 7,14 \\
\hline
\end{tabular}




\begin{tabular}{|c|c|}
\hline Professores & 21,42 \\
\hline Colegas & 28,57 \\
\hline Escritores/Booktubers & 14,28 \\
\hline Outro & 0,00 \\
\hline
\end{tabular}

Fonte: desenvolvido pelos autores (2020)

É possível que essa breve descrição - do que seria uma biblioteca esteja representada nos $92,85 \%$ dos discentes que "nenhuma vez" estiveram presentes na biblioteca do IFPE-Olinda para realizar leituras. Esse dado corrobora com: 34\% dos estudantes brasileiros que não frequentam a biblioteca; $19 \%$ dos brasileiros não vão a biblioteca porque não "gosta de ler" e 40\% porque "não tem tempo" (RETRATOS DA LEITURA, 2016). De acordo com a literatura, a biblioteca é um espaço essencial para a promoção e estímulo à leitura no âmbito pedagógico, além de desempenhar o papel da aproximação do aluno com a leitura (RAMOS, 2015; DURÁN; ESTEBAN, 2017; MOREIRA, 2010; BUFREM; SORRIBAS, 2009; LEMA, 2011; MONTEAGUDO, 2015; FERREIRA; BERSSANETTE, 2014; RODRÍGUEZ, 2012). Em relação ao cenário brasileiro, 13\% dos brasileiros indicaram que "ter internet" é o que faria frequentar mais vezes a biblioteca, sendo assim, identificou-se que a presença do aspecto "digital" não é o mais relevante.

Em continuidade, a pesquisa elenca os principais motivos para frequentá-la que são: "ter mais livros ou título novos" (32\%); "ter título interessantes ou que me agradem (22\%); e "ter atividades culturais" (15\%). (RETRATOS DA LEITURA, 2016).

Analisando-se as estatísticas da questão "formação do sujeitoleitor", temos: em primeiro lugar, $28,57 \%$ dos "colegas" influenciaram na leitura; em segundo, $21,42 \%$ dos discentes tiveram "nenhuma" influência no hábito da leitura e $21,42 \%$ dos discentes informaram que os "professores" foram os maiores influenciadores; em terceiro, somando-se os percentuais temos $14,28 \%$ dos discentes assinalando os "pais/mães/familiares" e 14,28\% correspondendo aos "escritores/booktubers".

O que chamou-nos atenção nesse quesito é que os "pais/mães/familiares", com 14,28\% não são os principais influenciadores da leitura dos discentes, mas, os "colegas" (JEFFMAN, 2017), com 28,57\%. Sendo assim, esse dado contraria, inicialmente, a literatura (PETIT, 2009; HIGA, 2007) e a pesquisa Retratos da Leitura (2016). Na pesquisa nacional, o grupo "outra pessoa" corresponde a $4 \%$ no tocante à influência pelo gosto da leitura, isto é, uma pessoa sem ligação familiar; a "mãe ou responsável do sexo feminino", o "pai ou responsável do sexo masculino" e "'algum outro parente" - somados - representam 19\%, sendo, os maiores responsáveis pela leitura do brasileiro. (RETRATOS DA LEITURA, 2016). 
Em relação à literatura, a estatística do questionário contradiz as pesquisas de vários autores, que estabelecem a família como mediadora entre a escola e o aluno, além de ter o papel transmissor do hábito da leitura para os mais jovens (PETIT, 2009; FLORES, 2011; PINHEIRO, 2016). Nesse sentido, "o hábito de leitura é uma construção [...] bastante influenciada por terceiros, especialmente por mães e pais, uma vez que os leitores, [...] também promovem essa experiência às crianças com as quais se relacionam [...]". (RETRATOS DA LEITURA, 2016, p. 131).

Podemos analisar - no questionário - a influência dos "professores" no hábito de ler, o qual corresponde ao percentual de $21,42 \%$. Na pesquisa nacional, em segundo lugar, temos $7 \%$ de "algum professor ou professora", como influenciador no gosto pela leitura do brasileiro (RETRATOS DA LEITURA, 2016). Em conformidade com a literatura, o papel do professor e/ou exemplo do professor em sala de aula - como modelo de leitor estimula os jovens a lerem ou serem potenciais leitores (HIGA, 2007; PINHEIRO, 2016; LEMA, 2011; ARÉVALO; GARCÍA; DÍAZ, 2014). Mesmo com esses dados, a pesquisa nacional indicou que 19\% dos "professores não indicam livros" (RETRATOS DA LEITURA, 2016). Esse percentual poderia ser analisado com mais profundidade, pois "[...] vai na contramão da resposta que diz que o professor é um incentivador fundamental para a leitura.". (CANÔNICA, 2016, p. 82).

No questionário, $21,42 \%$ dos discentes tiveram "nenhuma" influência no hábito da leitura. Comparando, nacionalmente, $67 \%$ dos brasileiros relataram que não tiveram nenhuma influência na leitura. É possível identificarmos que a ausência de "referenciais" - pais, mães, parentes, professores - na leitura para os mais jovens pode dificultar o crescimento e a formação do sujeito-leitor.

FIGURA 5: quadro com formação do Sujeito-leitor

\begin{tabular}{|c|c|}
\hline Em sua opinião, a principal importância da leitura, & $\%$ \\
\hline é formar um sujeito-leitor: & 85,71 \\
\hline Crítico & 7,14 \\
\hline Humanizado & 0,00 \\
\hline Erudito & 0,00 \\
\hline Político & 0,00 \\
\hline Emotivo/Afetivo & 7,14 \\
\hline Outro
\end{tabular}

Fonte: desenvolvido pelos autores (2020).

Neste quesito, $85,71 \%$ dos discentes afirmaram que à leitura visa à formação do sujeito-leitor crítico. Com 7,14\% o papel da leitura é uma 
formação humanizadora, ou "agregadora de conhecimento", ou seja, no quesito "outro" - os pesquisados afirmaram que a leitura não visa formar nenhum sujeito, apenas, transmitir conhecimento. De acordo com vários autores, a leitura crítica visa formar um sujeito-leitor autônomo, político e questionador. Ao estabelecer uma interação entre texto e contexto, teoria e prática, o sujeito-leitor omnilateral pode se apropriar dos elementos do trabalho, da ciência e da cultura e estabelecer uma visão transformadora da sua realidade. (RAMOS, 2008; SILVA; VIROTE, 2017; CIAVATTA, 2005). Nesse sentido, a formação do sujeito-leitor crítico preocupa-se em formar um ser pensante, integrado e humanizado.

FIGURA 6: TICs como ferramenta pedagógica de incentivo à leitura

Fonte: desenvolvido pelos autores (2020)

\section{Independente do curso (técnico, médio, superior), os professores deveriam utilizar com mais frequência as Tecnologias Informação e Comunicação (TICs) (tablets, redes sociais, aplicativos) para a realização de atividades pedagógicas voltadas à leitura? Justifique.}

"Sim. É muito importante ler, todo incentivo é bem-vindo. Ainda mais, atualmente, na era da tecnologia, é muito importante usar [as] 'TICs"'. (ALUNO B)

"Com mais frequência, pois é um meio mais acessível aos alunos". (ALUNA C)

"Sim, pois a diversidade do material que pode ser usado para a realização nesses casos é quase infinito". (ALUNO D)

"Sim. Porém, é muito difícil encontrar livros de computação gráfica com uma escrita simples". (ALUNA E)

"Sim, teria uma influência legal e mais rica no crescimento profissional". (ALUNO

"Os professores já usam bastante as TICs passando artigos". (ALUNO G)

"Sim, porque tem livros didáticos bem baratos ou fácil de se encontrar". (ALUNO

$\mathrm{H})$

"Sim, ajudaria mais os alunos com a aprendizagem digital e faria com que diminuísse mais o desmatamento para a produção de livros". (ALUNO I)

"Sim, a tecnologia está cada vez mais presente e facilita bastante o aprendizado e o acesso a aulas variadas". (ALUNO J)

"Sim, porque todos esses aparelhos e sistemas estimulam cada vez mais a leitura". (ALUNO K)

"É importante, pois estimula mais os jovens alunos". (ALUNA L)

"Sim, sempre que possível, algumas matérias nos deixam completamente distante do ato de escrita e leitura". (ALUNO M)

"Tablets, redes sociais e aplicativos facilitam a entrada de novos leitores". (ALUNO N)

"Sim. Isso tornaria as aulas mais interessantes e didáticas, fazendo o aluno se interessar mais pela matéria". (ALUNA O)

Fonte: desenvolvido pelos autores (2020)

Nesta questão, todos os discentes concordaram que a tecnologia é um componente inseparável das atividades pedagógicas que visam exercer à 
leitura em sala de aula, e cabe aos professores a introdução dessas ferramentas tecnológicas. Esta postura é identificada em várias pesquisas nacionais e internacionais - que identificam a necessidade do professor estar formado em TICs para aprofundar suas práticas de ensino e aprendizagem em sala de aula. (OLIVEIRA, 2013; LIBÂNEO, 2014; CRUZ; BIZELLI, 2015; RODRIGUES, 2009; COUTINHO; LISBÔA, 2011).

Compreender o uso das TICs e poder experimentar novos métodos de ensino que visem auxiliar a prática de leitura em sala de aula, é válido, no entanto, isto requer uma autoavaliação do docente para se desprender de "métodos tradicionais" e introduzir "métodos atuais" - digitais (ZACHARIAS, 2013). Ao promover essa mudança, os discentes podem desenvolver novas experiências de aprendizagem em sala de aula por meio dos recursos tecnológicos. Isso se comprova por meios das opiniões dos discentes:

Os professores já usam bastante as TICs passando artigos. (ALUNO G).

Sim, a tecnologia está cada vez mais presente e facilita bastante $o$ aprendizado e 0 acesso a aulas variadas. (ALUNO J).

Sim, porque todos esses aparelhos e sistemas estimulam cada vez mais a leitura. (ALUNO K).

Sim, sempre que possível, algumas matérias nos deixam completamente distante do ato de escrita e leitura. (ALUNO M).

Tablets, redes sociais e aplicativos facilitam a entrada de novos leitores. (ALUNO N).

Sim. Isso tornaria as aulas mais interessantes e didáticas, fazendo o aluno se interessar mais pela matéria. (ALUNA O).

É possível destacarmos que algumas opiniões dos pesquisados se centraram no aspecto da formação técnica profissional, desse modo, a utilização das TICs pode auxiliar na leitura de livros e outras atividades que tenham um foco utilitário (ORDINE, 2016; CARVALHO, 2013; CECCANTINI, 2016) da leitura para o crescimento profissional. 
Sim. É muito importante ler, todo incentivo é bem-vindo. Ainda mais, atualmente, na era da tecnologia, é muito importante usar [as] 'TICs. (ALUNO B).

Sim. Porém, é muito difícil encontrar livros de computação gráfica com uma escrita simples. (ALUNA E).

Sim, teria uma influência legal e mais rica no crescimento profissional. (ALUNO F).

A opinião seguinte traz afirmações relevantes para a compreensão da tecnologia e a historicidade da produção de livros:

Sim, ajudaria mais os alunos com a aprendizagem digital e faria com que diminuísse mais o desmatamento para a produção de livros. (ALUNO I).

De acordo com o discente, a utilização das TICs auxiliaria os alunos com a aprendizagem digital, ou seja, as obras e os livros por estarem instalados em plataformas tecnológicas não haveria a necessidade de os discentes recorrerem aos livros físicos. Além disso, o pesquisado aborda a questão do "desmatamento ambiental" presente na produção de livros. Essa visão - problematizadora - da realidade é fundamental para o discente compreender "[...] que qualquer processo de produção e/ou fenômeno social possui múltiplas dimensões e a sua compreensão exige que nós o vejamos como totalidade" (RAMOS, 2008, s/n), ou seja, qualquer conhecimento específico possui dimensões de caráter: político, econômico, histórico, ambiental etc. (RAMOS, 2008; CIAVATTA, 2005).

FIGURA 7: Book trailers em sala de aula 


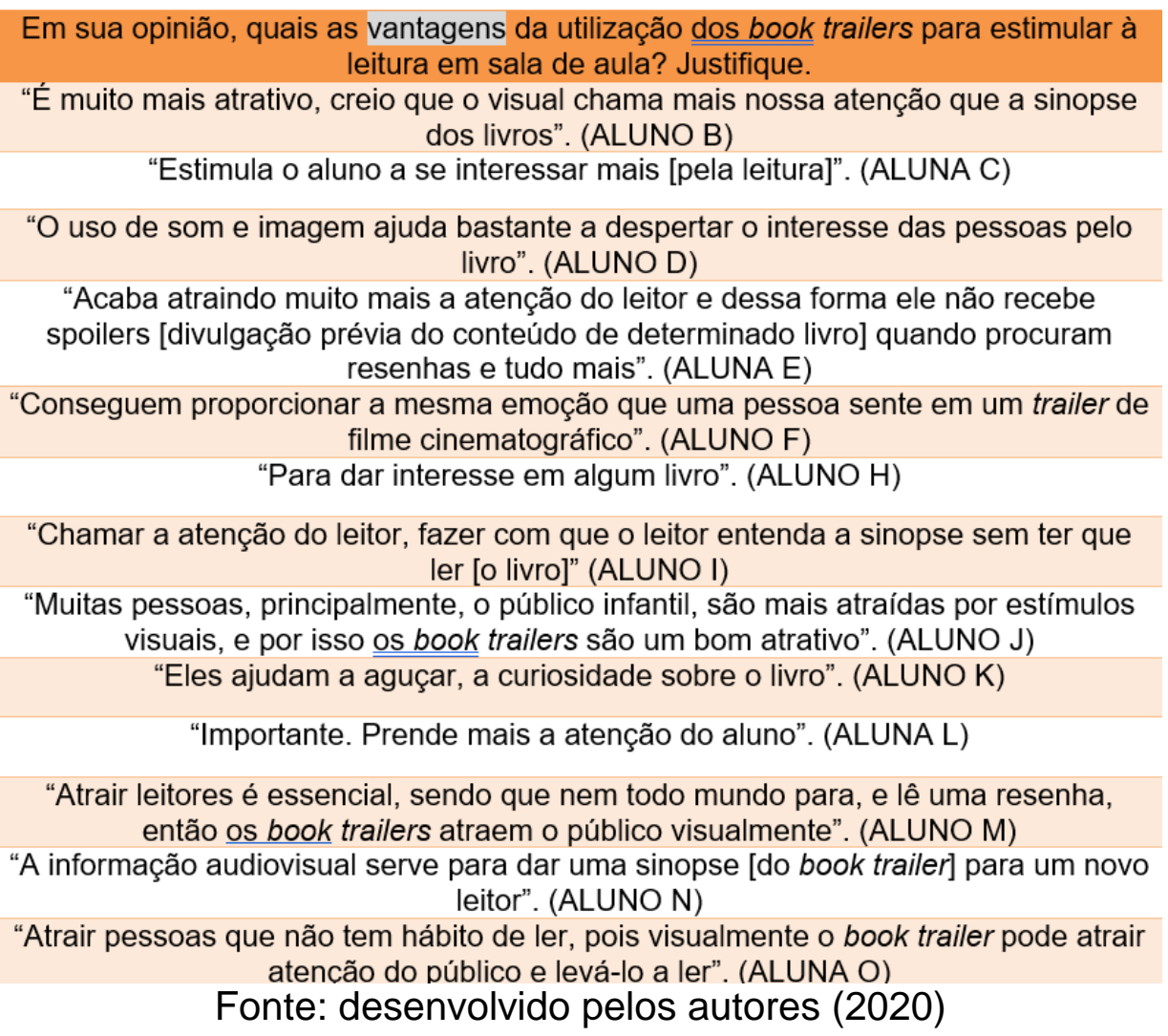

Segundo Sousa (2017), é possível que, no processo de criação dos book trailers, os alunos possam ir além de uma experiência de adaptação de um livro, mas que se converta em aprendizado. Nesse sentido, a aproximação do leitor com à leitura de determinado livro torna-se um processo natural, principalmente, despertando a curiosidade do leitor, por meio da apresentação dos momentos cruciais da história de uma obra. De acordo com esse excerto, os discentes afirmaram:

Estimula o aluno a se interessar mais [pela leitura]. (ALUNA C).

Para dar interesse em algum livro. (ALUNO H).

Chamar a atenção do leitor, fazer com que o leitor entenda a sinopse sem ter que ler [o livro]. (ALUNO I).

Eles ajudam a aguçar, a curiosidade sobre o livro. (ALUNO $\mathrm{K})$.

Importante. Prende mais a atenção do aluno. (ALUNA L). 
Essas opiniões corroboram com as pesquisas, que intensificam a importância das pessoas se apropriarem das TICs (p. ex. book trailers) para desenvolverem o hábito da leitura (VALERO; MARTíNEZ; FERNÁNDEZ, 2016) em sala de aula; o desenvolvimento de book trailers a partir do trabalho relacionado ao planejamento e criação de produções artísticas entrelaçadas com a leitura de livros clássicos (SANTOS, 2015); e propostas de trabalhos em grupo para a criação de book trailers possibilitando: novas experiências cognitivas, experiências interpessoais, interesses pela leitura e compreensão das novas tecnologias digitais. (MOREIRA; VEIGA, 2015).

Os discentes argumentaram sob diversas observações as vantagens da utilização dos book trailers para estimular à leitura em sala de aula. É sabido que essa tecnologia audiovisual ao apresentar uma narrativa literária desenvolve uma trama, juntando: cinema, literatura e tecnologia (MORAES; TREVISAN, 2014; RODRIGUES, 2015). Acerca desses aspectos, os discentes foram incisivos:

É muito mais atrativo, creio que o visual chama mais nossa atenção que a sinopse dos livros. (ALUNO B).

Conseguem proporcionar a mesma emoção que uma pessoa sente em um trailer de filme cinematográfico. (ALUNO F).

Atrair leitores é essencial, sendo que nem todo mundo para, e lê uma resenha, então os book trailers atraem o público visualmente". (ALUNO M).

A informação audiovisual serve para dar uma sinopse [do book trailer] para um novo leitor. (ALUNO N).

A estética dos book trailers é um dos traços marcantes dessa tecnologia educacional, e isto corrobora para chamar atenção dos leitores. Por selecionarem trechos escritos no impresso, os book trailers adaptam a linguagem do audiovisual com outras mídias, colocadas em diálogo com outras linguagens - trilha sonora, fotografia, sonoplastia etc. (RODRIGUES, 2015). Destarte, os book trailers podem "[...] ser utilizados como ferramentas de sinopse e simplificação do conteúdo de livros por meio da disposição de imagens e sons, de maneira a complementar ou a instigar a leitura do texto [...] (RODRIGUES, 2015, p. 202). Os aspectos visual, sonoro e imagético são mencionados - como forma de atrair os leitores - pelos discentes: 
O uso de som e imagem ajuda bastante a despertar o interesse das pessoas pelo livro. (ALUNO D).

Acaba atraindo muito mais a atenção do leitor e dessa forma ele não recebe spoilers [divulgação prévia do conteúdo de determinado livro] quando procuram resenhas e tudo mais. (ALUNA E).

Atrair pessoas que não tem hábito de ler, pois visualmente o book trailer pode atrair atenção do público e levá-lo a ler. (ALUNA O).

Muitas pessoas, principalmente, o público infantil, são mais atraídas por estímulos visuais, e por isso os book trailers são um bom atrativo. (ALUNO J).

O excerto do ALUNO $\mathrm{J}$ corrobora com as pesquisas internacionais ao identificarem que os leitores juvenis e infantis estão inseridos na rede digital, desse modo, os book trailers atuam como ferramentas destinadas a promoção da leitura pedagógica para esse público (TABERNERO-SALA, 2016; LLUCH; TABERNERO-SALA; CALVO-VALIOS, 2015; ROVIRACOLLADO, 2017). Do ponto de vista educacional, os book trailers auxiliam em novas formas de pensar a leitura e escrita em sala de aula, além de potencializar a promoção de livros infanto-juvenis no desenvolvimento literário e comunicativo. (IBARRA-RIUS; BALLESTER-ROCA, 2016).

\section{CONSIDERAÇÕES FINAIS}

O objetivo deste artigo foi investigar como a criação de book trailers, por discentes do Curso Técnico de Computação Gráfica do Instituto Federal de Pernambuco - Campus Olinda, pode contribuir para o estímulo à leitura em uma perspectiva de formação profissional e tecnológica. Inicialmente este artigo apresenta os resultados iniciais de uma pesquisa maior que está sendo desenvolvida no Programa de Pós-Graduação em Educação Profissional e Tecnológica do IFPE - Campus Olinda. Sendo assim, de acordo com os achados teóricos e empíricos, comprovou-se que o book trailer é uma ferramenta lúdica, emotiva e inovadora, no qual pode estimular o interesse, a curiosidade e o hábito da leitura para o sujeito-leitor.

De modo abrangente, conforme o questionário respondido pelos discentes, percebemos - ainda - a escassez de leitura do brasileiro; a ausência do discente nos espaços formais ( $p$. ex. biblioteca, sala de aula) para a realização da leitura; nas instituições de ensino a leitura está centrada numa perspectiva utilitarista/conteudística que dificulta a criação de novos 
leitores; os docentes possuem formação pedagógica precária para a utilização das TICs de incentivo à leitura em sala de aula, sendo assim, distanciando-se a leitura dos jovens discentes.

Por outro lado, há escassez de pesquisas nacionais acerca da criação e utilização dos book trailers como ferramenta didática de leitura e, a relevância do meio social - pais, amigos, familiares - para a formação do sujeito-leitor. Esse empecilhos foram identificados - em maior ou menor grau - na pesquisa de campo.

\section{REFERÊNCIAS}

ALMEIDA, L. R. S. de. Repensar e reaprender na era pós-digital. Revista de Administração de Empresas, v. 57, n.5, p. 520-521, set./out. 2017.

ANDRADE, L. C. de L. O Whatsapp como instrumento didático no processo de ensino-aprendizagem de leitura e de produção de textos. 2016. 156 f. Dissertação (Mestrado Profissional em Letras) - Universidade do Estado do Rio Grande do Norte, Natal, 2016.

ARÉVALO, J. A.; GARCíA, J. A. C.; DÍAZ, R. G. Comparación de los hábitos y perfil del lector digital entre Estados Unidos y España. Anales de

documentación, v. 17, n. 1, p. 1-16, 2014.

BUFREM, L. S.; SORRIBAS, T. V. Práticas de leitura em meio eletrônico. ETD - Educação Temática Digital, v. 11, n. 1, p. 298-326, dez. 2009.

CANÔNICA, V. A biblioteca, um barulho necessário de dentro para fora. In: FAILLA, Z. (Org.). Retratos da Leitura no Brasil 4. Rio de Janeiro: Sextante, 2016, p. 74-82.

CARVALHO, O. de. O mínimo que você precisa saber para não ser um idiota. 1. ed. Rio de Janeiro: Record, 2013.

CAVALCANTE, L. P. dos S. O ensino de leitura e o Facebook nas aulas de língua portuguesa. 2015. 121 f. Dissertação (Mestrado Profissional em Letras) - Universidade do Estado do Rio Grande do Norte, Natal, 2015.

CECCANTINI, J. L. Mentira que parece verdade: os jovens não leem e não gostam de ler. In: FAILLA, Z. (Org.). Retratos da Leitura no Brasil 4. Rio de Janeiro: Sextante, 2016, p. 83-98.

CIAVATTA, M. A formação integrada: a escola e o trabalho como lugares de memória e identidade. In: FRIGOTTO, G.; CIAVATTA, M.; RAMOS, M. (Org.). Ensino médio integrado: concepções e contradições. São Paulo: Cortez, 2005. p. 83-105.

COUTINHO, C.; LISBÔA, E. Sociedade da Informação, do Conhecimento e da Aprendizagem: desafios para educação no século XXI. Revista de Educação, Vol. XVIII, n. 1, p. 5-22, 2011.

CRESWELL, J. W. Projeto de pesquisa: métodos qualitativo, quantitativo e misto. 2. ed. Porto Alegre: Artmed, 2007. 
CRUZ, J. A. S.; BIZELLI, J. L. Docência para o ensino superior: inovação, informação e construção do conhecimento na era digital. Cadernos de Educação, Tecnologia e Sociedade, v. 8, n. 1, p. 79-90, 2015.

DURÁN, G. G.; ESTEBAN, N. De políticas de lectura en la era digital. In: CRUCES, F. (Dir.) et al. ¿Cómo leemos en la sociedad digital? Lectores, booktubers y prosumidores. Madrid: Fundación Telefónica y Editora Ariel, 2017, p. 207-230.

FARINACCIO, R. Entenda como a tecnologia não conseguiu matar os livros de papel. Tecmundo Online, 05 set. 2016. Disponível em:

$<$ https://www.tecmundo.com.br/literatura/109244-entenda-tecnologia-naoconseguiu-matar-livros-fisicos-papel.htm>. Acesso em: 11 ago. 2018.

FERNANDES, L. A.; GOMES, J. M. M. Relatórios de pesquisa nas ciências sociais: características e modalidades de investigação. ConTexto, v. 3, n.4, p. 1-23, 1ํ semestre, 2003.

FERREIRA, F.; BERSSANETTE, J. H. Uso do Facebook como ferramenta para promoção do hábito de leitura: uma experiência com alunos do curso técnico integrado ao ensino médio. In: IV SIMPÓSIO NACIONAL DE ENSINO DE CIÊNCIA E TECNOLOGIA, 27., 2014, Ponta Grossa, PR. Anais... Ponta Grossa, PR: SINECT, 2014.

FLORES, J. G. Hábitos lectores y competencias básicas en el alumnado de educación secundaria obligatoria. Educación XX1, v. 4, n. 1, p. 117-134, 2011.

GASKELL, G. Entrevistas individuais e grupais. In: BAUER, M. W.; GASKELL, G. (Orgs.). Pesquisa qualitativa com texto, imagem e som: um manual prático. Petrópolis: Vozes, 2002, p. 64-89.

GIL, A. C. Métodos e técnicas de pesquisa social. 6. ed. São Paulo: Atlas, 2008.

GUIDA, A. M. Leitura e tecnologias: modos de produzir, modos de ler. In: III CONGRESSO INTERNACIONAL DE LEITURA E LITERATURA INFANTIL E JUVENIL, 2012, Porto Alegre, RS. Anais... Porto Alegre, RS: CILLIJ PUCRS, 2012.

HIGA, S. E. L. A Constituição do sujeito leitor - duas histórias de mediação. 2007. 167 f. Trabalho de Conclusão de Curso (Graduação em Pedagogia) - Universidade Estadual de Campinas, Campinas, 2007.

IBARRA-RIUS, N.; BALLESTER-ROCA, J. Booktrailer en educación infantil y primaria: adquisición y desarrollo de las competencias comunicativa, digital y literaria a través de narrativas digitales. Digital Education Review, n. 30, p. 76-93, 2016.

INSTITUTO FEDERAL DE EDUCAÇÃO, CIÊNCIA E TECNOLOGIA DE PERNAMBUCO. Projeto Pedagógico - PPC Computação Gráfica.

Disponível em:

$<$ https://www.ifpe.edu.br/campus/olinda/cursos/tecnicos/subsequente/comput acao-grafica/projeto-pedagogico/PPCComputacaoGrafica final.pdf $>$. Acesso em: 25 jul. 2018. 
JEFFMAN, T. M. W. Booktubers: performances e conversações em torno do livro e da leitura na comunidade booktube. $2017393 \mathrm{f}$. Tese (Doutorado em Comunicação) - Universidade do Vale do Rio dos Sinos, São Leopoldo, 2017.

LEMA, M. de P. P. Pensamiento reflexivo para el aprendizaje de la lectura. Propuesta: elaboración y ejecución de una guía didáctica para docentes. 2011. 170 f. Proyeto Educativo (Licenciatura en las Ciencias de la Educación) - Universidad de Guayaquil, Equador, 2011.

LIBÂNEO, J. C. Adeus professor, adeus professora? São Paulo: Cortez, 2014.

LIMA, S. L. Práticas de leitura em meio digital e produção textual multimodal no ensino médio. In: IV SIMPÓSIO INTERNACIONAL E VIII SIMPÓSIO NACIONAL DE LITERATURA E INFORMÁTICA, 9., 2016, Passo Fundo, RS. Anais... Passo Fundo, RS: Universidade de Paço Fundo - UPF, 2016.

LIU, A. Does the brain like e-books? The New York Times Online, Estados Unidos, 14 de out. 2009. Disponível em:

$<$ https://roomfordebate.blogs.nytimes.com/2009/10/14/does-the-brain-like-ebooks/>. Acesso em: 25 jan. 2018.

MARQUES NETO, J. C. Retratos da Leitura no Brasil e as políticas públicas Fazer crescer a leitura na contracorrente - revelações, desafios e alguns resultados. In: FAILLA, Z. (Org.). Retratos da Leitura no Brasil 4. Rio de Janeiro: Sextante, 2016, p. 57-73.

MONTEAGUDO, B. C. da S. Biblioteca digital virtual e a leitura de textos em tabletes. 2015. 174 f. Dissertação (Mestrado em Educação) Universidade Estadual Paulista, Marília, 2015.

MORAES, L. P. de; TREVISAN, M. K. Book trailer: a busca estética de um novo formato audiovisual. Disciplinarum Scientia. v. 15, n. 1, p. 83-100, 2014.

MORAIS, J. K. C. de; HENRIQUE, A. L. S. Ensino Médio Integrado: fundamentos e intencionalidade formativa. In: ARAÚJO, A. C.; SILVA, C. N. N. da. (Orgs.). Ensino médio integrado no Brasil: fundamentos, práticas e desafios. Brasília: Ed. IFB, 2017, p. 419-433.

MOREIRA, M. A. O.; VEIGA, S. M. Projeto book trailers: uma tarefa pedagógica multimodal. In: VI SEMINÁRIO MÍDIAS \& EDUCAÇÃO DO COLÉGIO PEDRO II: "DISPOSITIVOS MÓVEIS E EDUCAÇÃO", 2015, São Cristóvão, RJ. Anais... São Cristóvão, RJ: COLÉGIO PEDRO II, 2015.

MOREIRA, M. A. Tecnologías digitales, multialfabetización y bibliotecas en la escuela del siglo XXI. Boletín de la Asociación Andaluza de

Bibliotecarios, n. 98-99, p. 39-52, 2010.

OLIVEIRA, E. D. Tecnologia e educação. In: XI ENCONTRO DE PESQUISADORES DO PROGRAMA DE PÓS-GRADUAÇÃO EM EDUCAÇÃO: CURRÍCULO. 29., 2013, São Paulo, SP. Anais... São Paulo, SP: Pontifícia Universidade Católica de São Paulo - PUC, 2013 
ORDINE, N. A utilidade do inútil: um manifesto. Rio de Janeiro: Zahar, 2016.

PETARNELLA, L.; GARCIA, E. de C. Homo Zappiens: educando na era digital. Conjectura, v. 15, n. 2, p. 175-179, maio/ago. 2010.

PETIT, M. A arte ler: ou como resistir à adversidade. São Paulo: Editora 34, 2009.

PINHEIRO, W. M. P. da S. A leitura como prática significativa na formação de leitores nas séries iniciais do ensino fundamental. 2016. 56f. Monografia (Licenciatura em Pedagogia) - Universidade Federal do Rio Grande do Norte, Natal, 2016.

PRESTES, M. L. de M. A pesquisa e a construção do conhecimento científico: do planejamento aos textos, a escola à academia. 2. ed. São Paulo: Rêspel, 2003.

RAMOS, M. Concepção do ensino médio integrado. Texto apresentado em seminário promovido pela Secretaria de Educação do Estado do Pará nos dias 8 e 9 de maio de 2008.

RETRATOS DA LEITURA NO BRASIL - 4ํㅡㄹição. Instituto Pró-Livro, São Paulo, mar. 2016. Disponível em:

http://prolivro.org.br/home/images/2016/Pesquisa Retratos da Leitura no $\mathrm{Br}$ asil - 2015.pdf. Acesso em: 10 fev. 2018.

RODRIGUES, N. C. Tecnologias de informação e comunicação na educação: um desafio na prática docente. Fórum Linguístico, v. 6, n. 1, p. 1-22, jan./jun. 2009.

RODRIGUES, R. T. P. Modos de leitura do jovem brasileiro contemporâneo: uma análise dos produtos híbridos audiolivro e livroclip. 2015. 401 f. Tese (Doutorado em Comunicação Social) - Universidade Federal do Rio de Janeiro, Rio de Janeiro, 2015.

RODRÍGUEZ, R. A. M. Bibliotecas, fomento de la lectura y redes sociales: convirtamos amigos en lectores. El profesional de la información, v. 21, n. 4, p. 401-405, 2012.

ROVIRA-COLLADO, J. Booktrailer y booktuber como herramientas LIJ 2.0 para el desarrollo del hábito lector. Investigaciones Sobre Lectura, n. 7, p. 55-72, 2017.

SANTAELLA, L. Para compreender a ciberliteratura. Texto Digital, v. 8, n. 2, p. 229-240, jul./dez. 2012.

SANTOS, D. T. dos. Envolvimento literário com book trailer. In: VI SEMINÁRIO MÍDIAS \& EDUCAÇÃO DO COLÉGIO PEDRO II: “DISPOSITIVOS MÓVEIS E EDUCAÇÃO”, 24., 2015, São Cristóvão, RJ. Anais... São Cristóvão, RJ: COLÉGIO PEDRO II, 2015.

SANTOS, I. L. dos; GIRÃO, I. P. T. Herói ou vilão? Reflexões sobre o uso dos book trailers na divulgação literária. In: ANAIS DO XVII ENCONTRO

REGIONAL DE ESTUDANTES DE BIBLIOTECONOMIA, DOCUMENTAÇÃO, 
CIÊNCIA E GESTÃO DA INFORMAÇÃO, 2., 2013, Fortaleza, CE. Anais... Fortaleza, CE: EREBD, 2013.

SAVIANI, D. Pedagogia histórico-crítica: primeiras aproximações. 11. ed. Campinas, SP: Autores Associados, 2011.

SILVA, S. P. da; VIROTE, C. Currículo Integrado no IF Goiano: possibilidades e desafios. In: ARAÚJO, A. C.; SILVA, C. N. N. da. (Orgs.). Ensino médio integrado no Brasil: fundamentos, práticas e desafios. Brasília: Ed. IFB, 2017, p. 141-149.

SOUSA, A. R. de. É você: book trailer, uma ferramenta para escritores iniciantes. 2017. 179 f. Monografia (Bacharelado em Publicidade e Propaganda) - Universidade Católica de Brasília, Distrito Federal, 2017.

SOUZA, R. M. de; COSTA, D. A. da. Livros em cartaz: o book trailere as novas formas de divulgação literária em tempos digitais. In: ENCONTRO NACIONAL DA UNIÃO LATINA DE ECONOMIA POLÍTICA DA INFORMAÇÃO, DA COMUNICAÇÃO E DA CULTURA, 4., 2012, Rio de Janeiro, RJ. Anais... Rio de Janeiro, RJ: ULEPICC, 2012.

TABERNERO-SALA, R. Los epitextos virtuales en la difusión del libro infantil: hacia una poética del book-trailer. Un modelo de análisis. Ocnos Revista de Estudios sobre Lectura, v. 15, n. 2, p. 21-36, 2016.

TABERNERO-SALA, R. T.; CALVO-VALIOS, V. Book-trailers as tools to promote reading in the framework of the Web 2.0. New Review of Children's Literature and Librarianship, v. 22, n. 1, p. 53-69, 2016.

THIOLLENT, M. Metodologia da pesquisa-ação. 18. ed. São Paulo: Cortez, 2011.

VALERO, A. L.; MARTÍNEZ, I. J.; FERNÁNDEZ, E. E. Aproximación educativa ante los nuevos formatos narrativos. Revista Chilena de Literatura, v. 94, p. 197-204, 2016.

ZACHARIAS, V. R. de C. Os ambientes digitais e as práticas de leitura: uma análise de atividades do Portal do Professor do MEC. 2013. $110 \mathrm{f}$. Dissertação (Mestrado em Linguística Aplicada) - Universidade Federal de Minas Gerais, Belo Horizonte, 2013. 